\title{
Estudo do Comportamento Empreendedor de Gestores em uma Instituição Pública de Ensino
}

\author{
Study of Entrepreneurial Behavior of Managers in a Public Education Institution
}

\author{
Cristina Aparecida Carneiro ${ }^{1}$ \\ Eloísa Helena Rodrigues Guimaraes² \\ Emerson Antônio Maccari ${ }^{3}$ \\ José Eduardo Storopoli ${ }^{4}$
}

\begin{abstract}
Resumo
A temática investigada neste artigo é o comportamento empreendedor voltado para a esfera pública. Objetivou-se verificar de que forma as características do comportamento empreendedor de gestores da Escola de Minas da Universidade Federal de Ouro Preto contribuem para o desenvolvimento de um ambiente empreendedor na instituição. Caracterizado como um estudo de caso, o estudo foi realizado por meio de pesquisa de campo com uma abordagem qualitativa. A coleta de dados foi realizada seguindo um roteiro semi estruturado, analisado por meio da técnica do discurso do sujeito coletivo. A abordagem comportamentalista de McClelland (1972) serviu de base para a construção do instrumento de pesquisa. Verificou-se que os gestores acompanham a tendência da gestão inovadora e criativa e parecem estar cientes tanto da importância da gestão empreendedora nas universidades como do que é necessário e o que dificulta sua implantação. Conclui-se que o desafio que se apresenta é criar ambientes que propiciem o desenvolvimento do espírito empreendedor e o aperfeiçoamento das características empreendedoras.
\end{abstract}

Palavras-chave: Empreendedorismo. Comportamento empreendedor. Instituições de Ensino Superior.

\begin{abstract}
The theme investigated by this article is entrepreneurial behavior toward the public sphere. The objective was to verify how the entrepreneurial behavior characteristics of managers of the Escola de Minas da Universidade Federal de Ouro Preto contributes to the development of an entrepreneurial environment in the institution. The behaviorist approach of McClelland (1972) formed the basis for the construction of the survey instrument. Characterized as a case study, this research was conducted through field research with a qualitative approach. Data collection was carried out following a semi-structured script, analyzed through the Collective Subject Discourse technique. It was found that the managers of the research institution follow the trend of innovative and creative management and appear to be aware of the importance of entrepreneurial management in universities, and also of what is needed and what hinders its implementation. It concludes that the challenge before us is to create environments that foster the development of entrepreneurship and improvement of behavioral characteristics.
\end{abstract}

Keywords: Entrepreneurship. Entrepreneurial behavior. Higher Education Institutions.

\section{Introdução}

Mudanças e transformações econômicas, políticas, tecnológicas e sociais estão influenciando as organizações, tanto na forma como são estruturadas quanto na maneira como produzem e distribuem

Mestre em Administração pela Faculdade Pedro Leopoldo - FPL Educacional. Brasil. Afiliação: FPL Educacional. Lattes: http://lattes.cnpq. br/3452287715661560 Email: tinacarneiros@hotmail.com

2 Professora do Mestrado Profissional em Administração da Fundação Pedro Leopoldo. Brasil. Afiliação: Fundação Pedro Leopoldo. Lattes: http://lattes.cnpq.br/6045354789038576 Email: eloisa.guimaraes@fpl.edu.br

3 Doutor em Administração pela Universidade de São Paulo. Professor Titular da Universidade Nove de Julho. Brasil. Afiliação: Universidade Nove de Julho. Lattes: http://lattes.cnpq.br/1320281388219996 Email: emersonmaccari@gmail.com

4 Doutor em Administração pela Universidade Nove de Julho. Professor de Ensino Superior da Universidade Nove de Julho. Brasil. Afiliação: Universidade Nove de Julho. Lattes: http://lattes.cnpq.br/2281909649311607 Email: storopoli@me.com 
seus produtos e serviços. Para Meyer Jr., Meyer e Rocha (2009), essas mudanças também influenciam a maneira como as organizações combinam os recursos, competem no mercado e servem à sociedade. Estes autores destacam que a tecnologia, a globalização e o novo papel do governo são as três principais forças que têm impulsionado as mudanças.

Entretanto, enquanto as contribuições e os desafios do empreendedorismo têm sido extensivamente estudados no setor privado, estudos sobre esse assunto são difíceis de serem encontrados no setor público (Emmendoerfer, Valadares, \& Balbi, 2008; Schmitz, 2012; Valadares, Emmendoerfer, Alves, \& Morais, 2012 Silva e Emmendoerfer, 2013).

Autores como Walter, Rocha, Domingues e Tontine (2007) e Lizote, Lana, Gauche e Verdinelli (2013) advertem que as instituições de ensino superior (IES) modelam seus processos administrativos mediante algumas condições desafiadoras para seus gestores e administradores, tais como: o volume significativo de recursos administrados; a quantidade de pessoas que participam direta ou indiretamente das atividades do sistema; o alto grau de autonomia dos professores; a necessidade de adequação das instituições frente à nova realidade, caracterizada por mudanças que influenciam a essência do trabalho acadêmico; o reconhecimento da importância da educação superior para o desenvolvimento do país, entre outras. Complementarmente, Marra e Melo (2007) explicam que os gestores universitários (reitores, pró-reitores, diretores de unidades, chefes de departamento, coordenadores de curso, entre outros), que são em sua grande maioria docentes que exercem a atividade acadêmica juntamente com as atividades gerenciais, são os responsáveis pelas respostas a esses desafios, geralmente sem uma adequação entre a formação técnica de professor e as práticas gerenciais.

Analisando as constantes mudanças e transformações econômicas, políticas, tecnológicas e sociais, sabe-se que administrar uma IES, sejam pública,seja privada, torna-se um papel cada vez mais desafiador para seus gestores, considerando-se que as organizações devem constituir uma massa crítica que permita a escolha, elaboração, implementação e avaliação de projetos inovadores (Fischborn, 2004).

De acordo com Vidal e Santos (2003), entre os autores que estudaram o comportamento empreendedor, destaca-se McClelland (1972), uma pesquisa realizada em 34 países identificando uma dezena de características de comportamento empreendedor (CCEs), comuns às pessoas triunfadoras. De acordo com McClelland, o sucesso empresarial não consiste apenas no desenvolvimento de habilidades específicas, tais como finanças, marketing e produção, nem apenas de incentivos creditícios e ou fiscais, mas também de habilidades atitudinais empreendedoras por meio do aperfeiçoamento de certas características.

Face ao contexto aqui delineado, a questão norteadora que se apresenta neste estudo é: Qual a relação entre as características comportamentais empreendedoras de gestores da Escola de Minas da Universidade Federal de Ouro Preto (UFOP) e o desenvolvimento de um ambiente empreendedor na instituição? Paralelamente, o objetivo geral da pesquisa foi verificar de que forma as CCEs de gestores da Escola de Minas da UFOP contribuem para o desenvolvimento de um ambiente empreendedor na instituição. Para alcançar esse objetivo principal, foram elencados como objetivos específicos: 1) verificar qual a concepção de empreendedorismo dos gestores; 2) identificar as características empreendedoras dos gestores segundo a abordagem comportamentalista de McClelland (1972); 3) analisar o ambiente da instituição quanto ao desenvolvimento das CCEs.

Este estudo justifica-se pela relevância e atualidade do tema - o empreendedorismo tem sido amplamente discutido e explorado por estudiosos, investidores, governantes, instituições públicas e privadas que o percebem como um instrumento de desenvolvimento econômico e social, demonstrando, assim, sua importância como um caminho para a inovação e a sua aplicabilidade às diversas instituições e pessoas. O estudo de Rosa et al (2015) sobre o estado da arte dos estudos sobre empreendedorismo aponta que, no período compreendido entre os anos de 2005 a 2014, houve um aumento significativo de publicações sobre esse tema. Justifica-se também por abordar um tema ainda não estudado na UFOP - uma instituição que oferece 42 cursos de graduação, sendo 38 presenciais e 5a distância, 22 cursos de mestrado e 9cursos de doutorado. Com o papel do empreendedor cada vez mais valorizado, torna-se 
relevante analisar as características dos servidores públicos, o que poderá contribuir para o desenvolvimento da cultura empreendedora na instituição.

\section{Referencial teórico}

No Brasil, o movimento do empreendedorismo começou a tomar forma na década de 1990, quando entidades como o Serviço Brasileiro de Apoio às Micro e Pequenas Empresas (SEBRAE) e a Sociedade Brasileira para Exportação de Software (SOFTEX) foram criadas. Antes disso, Dornelas (2008) explica que praticamente não se falava em empreendedorismo e em criação de pequenas empresas. Os ambientes político e econômico do país não eram propícios, e o empreendedor praticamente não encontrava informações para auxiliá-lo na jornada empreendedora. Atualmente, percebe-se o movimento de apoio ao empreendedorismo sair da esfera do SEBRAE e atingir organizações não governamentais, a iniciativa privada, associações, instituições de ensino e a mídia em geral. Para o autor, as mudanças, que começaram a partir da década de 1990, com o advento da tecnologia da informação em larga escala, proporcionaram às organizações uma agilidade e flexibilidade sem precedentes na história, obrigando as empresas a reverem suas estruturas para melhor se adequarem ao ritmo de dinamismo que se criou neste novo mundo.

Filion (1999) e Valadares et al.(2012), entre outros, esclarecem que dois enfoques se destacam nos estudos sobre empreendedorismo: o econômico e o comportamental. O enfoque econômico é associado à inovação, representado por Schumpeter (1982), no qual os empreendedores promovem a "destruição criativa", processo definido como sendo o impulso fundamental que aciona e mantém em marcha o motor capitalista, constantemente criando novos produtos, novos modos de produção e novos mercados, sobrepondo-se aos antigos métodos, menos eficientes e mais caros. Já o enfoque comportamental é associado a características dos indivíduos empreendedores, representado por McClelland (1972) ao relacionar o conceito de empreendedor à necessidade de sucesso, de reconhecimento, de poder e controle.

Valadares et al. (2012) explicam que, para Sadler (2000), a noção de empreendedorismo apregoada pelos economistas é associada à capacidade do homem, enquanto empreendedor, para inovar e poder contribuir para o desenvolvimento local da economia. Essa noção pode ter intensas influências do sistema de produção em vigor na época dos clássicos da economia, em que o indivíduo era considerado uma mera extensão da máquina produtiva. Na tentativa de compreender a figura do empreendedor, ou seja, da pessoa que age de forma empreendedora, a perspectiva comportamental importou importantes conceituações da teoria de recursos humanos para a teoria do empreendedorismo. Essa perspectiva focou na descrição de um perfil empreendedor.

Schmitz (2012) enfatiza que pesquisas na área do empreendedorismo podem facilitar o entendimento das transformações que estão ocorrendo no ciclo evolutivo das instituições, de como se processam os desdobramentos da valorização do empreendedor no mercado e identificar necessidades, movimentos e tendências para, a partir daí, buscar e/ou utilizar o conhecimento adequado e eficaz.

\subsection{Intraempreendedorismo e sua importância para as organizações}

Até a década de 1970, as pesquisas sobre empreendedorismo priorizavam as ações e características individuais dos empreendedores. No entanto, a partir de 1980, foram desenvolvidas pesquisas que buscavam compreendera noção de empreendedorismo dentro das organizações. Surgiu, assim, o empreendedorismo corporativo, definido como o estudo do comportamento empreendedor dentro das organizações (Hashimoto, 2009).

O conceito de intraempreendedor foi introduzido pelo economista GifordPinchot (1989, p. xi) como "aquele que assume a responsabilidade pela criação de inovações de qualquer espécie dentro de uma organização. O intraempreendedor pode ser o criador ou inventor, mas é sempre o sonhador que concebe como transformar uma ideia em uma realidade lucrativa". 
Para Pinchot (1989), o que diferencia o intraempreendedor do empreendedor é que o primeiro atua de forma empreendedora inserido em uma organização já existente, enquanto o segundo atua criando novas organizações e negócios.

Paralelamente a essa concepção, Prado, Machado, Melo e Lapolli (2011) destacam que as características básicas dos intraempreendedores são parecidas com as dos empreendedores, e que possuem base nas necessidades, aptidões, conhecimentos e valores. O intraempreendedor deseja permanecer na empresa onde trabalha e é orientado para a ação quando recebe liberdade, recursos e incentivo da empresa.

É importante observar que as características do intraempreendedor, ou empreendedor corporativo, são transferidas para a cultura organizacional, resultando na cultura corporativa. A verificação e consequente análise das políticas de recursos humanos, a forma como a inovação e a aprendizagem são vistas pela empresa, a organização do trabalho, bem como a análise do processo estratégico, podem fornecer subsídios para compreender os fenômenos que trazem como resultado a competitividade e a renovação organizacional (Prado et al., 2011).

\subsection{Ambiente e comportamento empreendedor}

Ao fazer referência a estudos sobre o comportamento empreendedor, Barlach (2014) destaca que se verifica um grande número de citações às pesquisas desenvolvidas por McClelland nas décadas de 1960 e 1970. Segundo Wolf (2014), o marco inicial do projeto idealizado por McClelland foi um estudo realizado em 34 países para identificar características de comportamento comuns aos empreendedores bem-sucedidos; em seguida, foram realizados instrumentos de seleção e treinamento que promoveram o desenvolvimento de algumas características apuradas na pesquisa.

O projeto, com sua formatação definitiva, foi lançado oficialmente pela Organização das Nações Unidas (ONU) no ano de 1988, na Argentina, sendo em seguida aplicado nos seguintes países: Chile, Uruguai, Venezuela, Gana, Nigéria e Zimbábue. No ano de 1990, o programa começou a ser desenvolvido no Brasil através de convênio do SEBRAE com a ONU (Barlach, 2014).

Em seus estudos, McClelland identificou dez principais características comportamentais que o empreendedor bem-sucedido deve ter, desenvolver, ou apenas aprimorar, agrupados em três conjuntos: realização, planejamento e poder. O autor enfatiza que o conhecimento das características e habilidades que compõem as competências empreendedoras, e também de como podem ser desenvolvidas pelos empreendedores, auxilia a compreensão do comportamento empreendedor. Com esse entendimento, o comportamento empreendedor pode ser descrito por suas ações executadas em determinadas situações, que envolvem suas atitudes e habilidades (Schmitz, 2012). São apresentadas na figura 1as características do comportamento empreendedor identificadas por McClelland.

\begin{tabular}{|l|}
\hline CONJUNTO: REALIZAÇÃO \\
\hline Característica: Busca de oportunidades e iniciativa. Comportamentos manifestados: \\
Faz as coisas antes de solicitado ou antes de ser forçado pelas circunstâncias; \\
Age para expandir o negócio a novas áreas, produtos ou serviços; \\
Aproveita oportunidades fora do comum para começar um negócio. \\
\hline Característica: Persistência. Comportamentos manifestados: \\
Age diante de um obstáculo significativo; \\
Age repetidamente ou muda de estratégia para enfrentar um desafio; \\
Faz um sacrifício pessoal ou desenvolve um esforço extraordinário para completar uma tarefa. \\
\hline Característica: Comprometimento. Comportamentos manifestados: \\
Assume responsabilidade pessoal pelo desempenho necessário para atingir metas e objetivos; \\
Colabora com os empregados ou se coloca no lugar deles, se necessário, para terminar um \\
trabalho; \\
Esmera-se em manter os clientes satisfeitos e coloca em primeiro lugar a boa vontade em longo \\
prazo, acima do lucro em curto prazo.
\end{tabular}




\begin{tabular}{l} 
Característica: Exigência de qualidade e eficiência. Comportamentos manifestados: \\
Encontra maneiras de fazer as coisas melhorarem mais rápido ou mais barato; \\
Age de maneira a fazer coisas que satisfazem ou excedem padrões de excelência; \\
Desenvolve ou utiliza procedimentos para assegurar que o trabalho seja terminado a tempo ou que \\
o trabalho atenda a padrões de qualidade previamente combinados. \\
\hline Característica: Capacidade de correr riscos calculados. Comportamentos manifestados: \\
Avalia as alternativas e calcula riscos deliberadamente; \\
Age para reduzir os riscos ou controlar os resultados; \\
Coloca-se em situações que implicam desafios ou riscos moderados. \\
\hline CONJUNTO: PLANEJAMENTO \\
\hline Característica: Busca de informações. Comportamentos manifestados: \\
Dedica-se pessoalmente a obter informações de clientes, fornecedores e concorrentes; \\
Investiga pessoalmente como fabricar um produto ou fornecer um serviço; \\
Consulta especialistas para obter assessoria técnica ou comercial. \\
\hline Característica: Estabelecimento de metas. Comportamentos manifestados: \\
Estabelece metas e objetivos que são desafiantes e que têm significado pessoal; \\
Define metas de longo prazo, claras e específicas; \\
Estabelece objetivos mensuráveis e de curto prazo. \\
\hline Característica: Planejamento e monitoramento sistemáticos. Comportamentos manifestados: \\
Planeja, dividindo tarefas de grande porte em subtarefas com prazos definidos; constantemente \\
revisa seus planos levando em conta os resultados obtidos e as mudanças circunstanciais; \\
Mantém registros financeiros e utiliza-os para tomar decisões. \\
\hline CONJUNTO: PODER \\
\hline Característica: Independência e autoconfiança. Comportamentos manifestados: \\
Busca autonomia em relação a normas e controles de outros; \\
Mantém seu ponto de vista mesmo diante da oposição ou de resultados inicialmente desanimadores; \\
Expressa confiança na sua própria capacidade de completar uma tarefa difícil ou de enfrentar um \\
desafio. \\
\hline Característica: Persuasão e redes de contato. Comportamentos manifestados: \\
Utiliza estratégias deliberadas para influenciar ou persuadir os outros; \\
Utiliza pessoas chave como agentes para atingir seus próprios objetivos; \\
Age para desenvolver e manter relações comerciais. \\
\hline
\end{tabular}

Figura 1 - Características comportamentais empreendedoras identificadas por McClelland Fonte: Adaptado de Vidal, F. A. B. \& Santos, J. L. F. (2003).

As CCEs estão apresentadas em três conjuntos. É possível perceber que as características enquadradas no primeiro conjunto são relativas às pessoas que desejam realizar o seu trabalho da melhor forma possível, que não desanimam diante dos obstáculos e que agem para reduzir os riscos e controlar os resultados. No segundo conjunto, são relativas às pessoas que planejam as atividades e estabelecem metas; e, no terceiro conjunto, listam-se características de pessoas que buscam autonomia, assumem suas responsabilidades e se esforçam para manter o controle sobre as situações e as pessoas.

A relevância das pesquisas de McClelland (1961) consiste em sua abordagem sobre as características das pessoas bem-sucedidas. As habilidades técnicas específicas, como marketinge finanças, são essenciais, de forma que as CCEs fazem a diferença e, o mais importante, elas podem ser desenvolvidas (WOLF, 2014). Barlach (2014) reforça essa afirmação ao destacar que, para McClelland, não havia relação consistente entre genética e empreendedorismo, mas, sim, entre meio ambiente e empreendedorismo. A necessidade de realização seria desenvolvida a partir da cultura, das experiências e da aprendizagem. Os traços que caracterizariam os empreendedores não seriam constitucionais, mas moldados pelo ambiente.

\subsection{0 contexto do empreendedorismo em instituições públicas de ensino superior}

O fenômeno empreendedorismo já foi mais reservado ao setor privado.Atualmente, tem despertado o interesse do setor público como forma de gerir a escassez de recursos, inovar e renovar as organizações 
públicas (Marques, 2014). Na concepção de Prado et al. (2011), nas empresas privadas a motivação está relacionada à sua sobrevivência e competitividade no mercado,enquanto nas empresas públicas essa motivação está relacionada à capacidade de cumprir sua missão, ou seja, atender com qualidade a prestação de serviços de interesse da sociedade. Focando a realidade empresarial brasileira, constatase que as organizações nacionais, tanto públicas como privadas, já desenvolvem esforços no sentido de recuperar o tempo perdido, de pelo menos duas décadas, que as levaram a um atraso em relação à situação mundial.

Wolf (2014) esclarece que, ante as novas prerrogativas estruturais da gestão das organizações públicas no Brasil e as mudanças no cenário mundial, o profissional da educação pública precisa investir na sua carreira profissional. Para que haja uma transformação proporcional às prerrogativas ditadas pela era da gestão do conhecimento, as condutas profissionais também se modificaram. Espera-se que a inserção de competências e a entrega de conhecimentos, habilidades e atitudes individuais ao coletivo - nesse caso, a instituição pública - sejam meios capazes de cumprir esse objetivo, organizando o trabalho, os conteúdos e os métodos utilizados.

No entanto, Coelho (2010) e Valadares et al. (2012) advertem que as organizações públicas possuem características próprias (rotinas, hierarquia excessiva, descontinuidade, paternalismo etc.), que constituem verdadeiros obstáculos para inovações e mudanças,opondo-se ao empreendedorismo, tornando a adaptação ao empreendedorismo complexa.

Paralelamente, Prado et al. (2011) esclarecem que o intraempreendedorismo ocorre por meio da força de vontade das pessoas de empreender na organização, seja uma empresa privada,seja pública, bem como em universidades. Os autores ressaltam que as universidades são instituições complexas e as políticas públicas de desenvolvimento realizadas na última década pelo governo federal, os planos de reestruturação das universidades federais e os programas de inclusão social trazem grandes desafios a serem enfrentados pelas instituições universitárias, que são instituições sociais que buscam a educação permanente e continuada na era do conhecimento.

\section{Metodologia}

Para atingir os objetivos propostos neste estudo, optou-se por realizar uma pesquisa descritiva. Quanto aos meios, caracteriza-se como um estudo de caso, tendo sido realizada por meio de pesquisa de campo com uma abordagem qualitativa. Nesta pesquisa, a unidade de análise é a Escola de Minas da UFOP, e a unidade de observação são os profissionais que ocupam diferentes cargos de gestão na Escola de Minas.

A coleta de dados foi realizada por meio de entrevistas, seguindo um roteiro semi estruturado, com perguntas abertas e fechadas, adaptado de Fischborn (2004), cujo objetivo foi estudar o perfil empreendedor dos administradores de IES de Santa Catarina.

A análise dos dados qualitativos, coletados a partir das perguntas abertas, foi realizada por meio da técnica do Discurso do Sujeito Coletivo (DSC), descrita por Figueiredo, Chiari e Goulart (2013) como uma técnica de tabulação e organização de dados qualitativos que foi desenvolvida por Lefèvre e Lefèvreno fim da década de 90,tendo como fundamento a teoria da Representação Social, que consiste em esquemas sociocognitivos que as pessoas utilizam para emitirem juízos ou opiniões, acessíveis por meio de depoimentos individuais.

Lefèvre e Lefèvre (2006) esclarecem que, para o DSC, o pensamento coletivo, que expressa uma dada representação social, oferece uma dupla representatividade - qualitativa e quantitativa - das opiniões coletivas que emergem da pesquisa. É qualitativa porque, na pesquisa, com o DSC, cada distinta opinião coletiva é apresentada sob a forma de um discurso que recupera os distintos conteúdos e argumentos,os quais conformam uma dada opinião na escala social; e é quantitativa, porque tal discurso tem também uma expressão numérica que indica quantos depoimentos, do total, foram necessários para compor cada DSC.Assim sendo, confere confiabilidade estatística, considerando-se as sociedades como coletivos de indivíduos. 
A partir daí, montou-se um processo de organização de depoimentos verbais que, por meio das figuras metodológicas da Ideia Central (IC), das Ancoragens (AC), das Expressões Chave (ECH) e do Discurso do Sujeito Coletivo (DSC), permitiram, ao final, construir discursos síntese, redigidos na primeira pessoa do singular. Eles reúnem em si as $\mathrm{ECH}$, isto é, trechos literais dos depoimentos individuais que tem IC de sentido reputado equivalente ou semelhante (Lefèvre\&Lefèvre, 2004). Os dados quantitativos foram tabulados via Microsoft Excel 2010.

\section{Apresentação e discussão dos resultados}

A UFOP, sediada na cidade de Ouro Preto, tem sua origem nas tradicionais ecentenárias Escola de Farmácia e Escola de Minas. A Escola de Farmácia, a primeira do gênero da América Latina, foi fundada em 04 de abril de 1839. A Escola de Minas foi fundada em 12 de outubro de 1876, pelo francês Claude Henri Gorceix, a pedido do Imperador D. Pedro II. Segunda Escola de Engenharia implantada no país, a Escola de Minas é a responsável pela formação, entre outros, de profissionais nas áreas de geologia, mineração e metalurgia. A partir da união dessas escolas, em 21 de agosto de 1969, foi criada a UFOP, e desde então a instituição tem ampliado seu espaço, com novos cursos e campi (Resolução CUNI 1174/2010).

A Escola de Minas é hoje uma das 11 unidades acadêmicas que compõem a UFOP. Integram-na 8 departamentos que oferecem 9 cursos de graduação (Engenharia Geológica, de Minas, Metalúrgica e de Materiais, Civil, Ambiental, de Controle e Automação, Mecânica, Produção e Arquitetura e Urbanismo). Além disso, oferece 5 programas de mestrado e doutorado acadêmicos além de 2 programas de mestrado profissional (UFOP, 2015).

\subsection{Resultados das entrevistas}

Com o objetivo de verificar qual a concepção de empreendedorismo dos gestores, foram elaboradas quatro questões: $\mathrm{O}$ que você entende por empreendedorismo?O que é um empreendedor no ambiente universitário? Você considera o empreendedorismo importante como forma de gestão nas universidades? O que você propõe como ação empreendedora na universidade?

Devido ao grande número de dados gerados, será apresentado neste artigo apenas o DSC de cada questão, redigido a partir da categoria com maior porcentagem de respostas.

As ideias Centrais (IC) de sentido semelhante, ou complementar, relativas à primeira questão foram agrupadas em categorias, denominadas por uma expressão síntese que indicou o sentido dos depoimentos reunidos e podem ser observadas na tabela 1 , bem como o resultado quantitativo desta questão.

Tabela 1 - Categorias, IC e resultados quantitativos da questão "O que você entende por empreendedorismo?"

\begin{tabular}{clcc}
\hline \multirow{2}{*}{ Categoria } & Ideias centrais & \multicolumn{2}{c}{ Resultados quantitativos } \\
\cline { 3 - 4 } & Motivação para inovar, mudar e criar. & 06 & Porcentagem \\
\hline A & Desenvolvimento de ideias, projetos e serviços. & 08 & 21,43 \\
B & Criação de uma empresa ou negócio. & 08 & 28,57 \\
C & Implementação de produtos e serviços em uma empresa já & 06 & 28,57 \\
D & existente. & & 21,43 \\
\hline
\end{tabular}

Fonte: Dados da pesquisa

A tabela 1 revela que as ideias e definições relativas à questão estão compartilhadas e distribuídas de forma bastante homogênea entre os pesquisados e que elas não são divergentes, mas sim complementares. A partir das respostas agrupadas na categoria B, foi elaborado o DSC 1: Entendo que empreendedorismo é o processo de iniciar algo novo gerando resultados positivos. É a iniciativa e habilidade para planejar, gerenciar e concluir ideias e projetos assumindo todos os riscos previsíveis. Refere-se às pessoas que iniciam e desenvolvem atividades gerando resultados que resultem na promoção do desenvolvimento econômico pessoal e social. 
Analisando o DSC 1, observa-se que o pensamento coletivo dos gestores revela que o empreendedorismo está relacionado ao desenvolvimento de ideias, projetos e serviços. Dornelas (2008) esclarece que empreendedorismo é o envolvimento de pessoas e processos que, em conjunto, levam à transformação de ideias em oportunidades.Compartilhando desse conceito, Filion (1999) complementa que empreendedores são indivíduos que precisam continuar a aprender, não somente o que está acontecendo no seu ambiente, mas a detectar novas oportunidades e tomar as decisões para implantá-las. Para esse autor, os empreendedores são pessoas que geram ou aproveitam oportunidades e criam valor tanto para si como para a sociedade. Na tabela 2, podem ser observadas as ICs e os dados quantitativos relativos à segunda questão.

Tabela 2 - Categorias, IC e resultados quantitativos da questão "O que é um empreendedor no ambiente universitário?"

\begin{tabular}{clcc}
\hline & & \multicolumn{2}{c}{ Resultados quantitativos } \\
\cline { 2 - 4 } Categoria & Ideias centrais & Número & Porcentagem \\
\hline A & Ter visão de futuro. & 05 & 17,86 \\
B & Elaborar, implantar e gerenciar projetos. & 03 & 10,71 \\
C & Conceber e promover novas formas de transmissão do & 09 & 32,14 \\
D & conhecimento. & & 21,43 \\
E & Ser um gestor não burocrático. & 06 & 10,71 \\
--- & Ser dedicado ao trabalho. & 03 & 3,57 \\
--- & Resposta que não se enquadrou em nenhuma categoria. & 01 & 3,57 \\
\hline
\end{tabular}

Fonte: Dados da pesquisa

Observa-se que as ideias e definições relativas à questão não estão compartilhadas e difundidas de forma tão homogênea entre os pesquisados como na questão anterior. A partir das respostas agrupadas na categoria C, foi elaborado o DSC 2: Para mim, um empreendedor no ambiente universitário é aquele concebe e promove novas formas de transmissão e aplicação do conhecimento e o coloca à disposição da comunidade. É aquele profissional que estimula o ensino crítico e contextualizado para que não se formem somente gestores de recursos com um conteúdo puramente técnico-científico, mas gestores capazes de propor ideias inovadoras em benefício comum. Enfim, é aquele que promove a transformação de conhecimentos em produtos ou serviços, contribuindo para o crescimento da economia, melhoria da qualidade de vida da população e para a competitividade das empresas.

O DSC 2 indica que os gestores relacionam o empreendedorismo no ambiente universitário à concepção e promoção de novas formas de conhecimento. Nesse contexto, Meyer Jr. et al. (2009) abordam que a sociedade atual destaca-se pelo capital intelectual, um fator estratégico e diferenciador entre as organizações,pois o conhecimento é o principal recurso que uma organização, país ou região pode dispor para manter-se atuante de forma produtiva e relevante para a sociedade. 
As IC referentes à terceira questão estão relacionadas na tabela 3, bem como o resultado quantitativo da questão.

Tabela 3 - Categorias, IC e resultados quantitativos da questão "Você considera o empreendedorismo importante como forma de gestão nas universidades? "

\begin{tabular}{llcc}
\hline \multirow{2}{*}{ Categoria } & Ideias centrais & \multicolumn{2}{c}{ Resultados quantitativos } \\
\cline { 3 - 4 } & Número & Porcentagem \\
\hline A & $\begin{array}{l}\text { É uma forma de ultrapassar as limitações próprias de uma } \\
\text { instituição pública. }\end{array}$ & 10 & 35,71 \\
B & $\begin{array}{l}\text { Pode resultar no desenvolvimento de uma cultura } \\
\text { empreendedora. }\end{array}$ & 09 & 32,14 \\
C & $\begin{array}{l}\text { É uma força poderosa para mudar o perfil socioeconômico de } \\
\text { um país. }\end{array}$ & 05 & 17,86 \\
--- & Sem resposta. & 02 & 7,14 \\
-- & Resposta que não se enquadrou em nenhuma categoria. & 02 & 7,14 \\
\hline
\end{tabular}

Fonte: Dados da pesquisa

A tabela 3 revela que as ideias e definições relativas à questão estão compartilhadas e difundidas de forma bastante homogênea entre os pesquisados, houve grande semelhança nas respostas. A partir das respostas agrupadas na categoria A, foi elaborado o DSC 3: Sim, pois o empreendedorismo como forma de gestão é importante para ultrapassar as limitações, as barreiras, e a falta de recursos, suprindo as dificuldades e as lacunas próprias de uma instituição pública. É preciso novas ideias e visões para se conseguir mais com os mesmos recursos. Uma gestão empreendedora propicia iniciativas empreendedoras, um bom desenvolvimento do trabalho, soluções efetivas para a instituição;enfim, é um estímulo à inovação e criatividade. Acredito que as ações resultantes do empreendedorismo sempre levam ao crescimento e ao aperfeiçoamento das técnicas ou do meio existente nas universidades;é uma de forma cultivar as relações entre o ensino, a pesquisa e a extensão. No meu entendimento, se não houver o empreendedorismo a universidade torna-se apenas um colégio de $3^{\circ}$ grau;por meio do empreendedorismo, o gestor é capaz de inovar e acompanhar as transformações do mundo, adaptando-se a elas.

Ficou bem evidenciado que os pesquisados consideram o empreendedorismo uma importante forma de gestão das universidades, seja por sua importância para ultrapassar as limitações próprias de uma instituição pública, porque pode resultar no desenvolvimento de uma cultura empreendedora, seja por sua força poderosa para mudar o perfil socioeconômico de um país.

As IC relativas e o resultado quantitativo da quarta questão podem ser observados na tabela 4.

Tabela 4 - Categorias, IC e resultados quantitativos da questão -"O que você propõe como ação empreendedora na universidade?"

\begin{tabular}{llcc}
\hline & & \multicolumn{2}{c}{ Resultados quantitativos } \\
\cline { 2 - 4 } Categoria & Ideias centrais & Número & Porcentagem \\
\hline A & Uso da tecnologia e gestão das atividades pedagógicas. & 06 & 21,43 \\
B & Incentivo à criação e organização de projetos e eventos & 10 & 35,71 \\
C & acadêmicos e científicos. & 02 & 7,14 \\
D & Investimento na gestão de recursos humanos. & 03 & 10,71 \\
--- & Mudança da cultura organizacional. & 04 & 14,29 \\
-- & Sem resposta. & 03 & 10,71 \\
\hline
\end{tabular}

Fonte: Dados da pesquisa

A tabela 4 revela como as ideias e definições relativas à questão estão compartilhadas e difundidas entre os pesquisados. A partir das respostas agrupadas na Categoria B, foi elaborado o DSC 
4: O empreendedorismo de mercado pode ser estimulado por meio do fomento ao empreendedorismo universitário, por ser uma ferramenta que permite ao aluno o contato direto com experiências do mercado e contribui para a melhoria do aprendizado. Várias ações podem ser enumeradas: criação de disciplina/ cursos sobre empreendedorismo; busca de parcerias externas para financiamento de projetos e incentivo à cooperação entre universidades, empresas e governo; organização de projetos e eventos acadêmicos e científicos, tais como: empresas juniores, incubadoras de empresas, atividades de extensão em geral, projetos, concursos de ideias, simpósios, feiras,entre outros eventos. Outra ação muito importante é o estímulo à rede de contato entre alunos e egressos, favorecendo a constituição de um ambiente mais propício ao empreendedorismo.

ODSC 4 indicou que os entrevistados compreendem o incentivo à criação e organização de projetos e eventos acadêmicos e científicos como uma ação empreendedora na universidade. Marques (2014) confirma que essas ações contribuem para o desenvolvimento do empreendedorismo dentro das universidades e acrescenta que a questão da pesquisa e do desenvolvimento tecnológico são vitais para o setor produtivo de um país como o Brasil, onde não há essa tradição. Entretanto, a autora alerta que isso somente é possível com o envolvimento de um maior número de pessoas que compartilhem dessa ideia e queiram tornar a universidade mais aberta aos setores produtivos, criando uma verdadeira corrente de desenvolvimento.

\subsubsection{Características empreendedoras no âmbito profissional}

A terceira parte do roteiro de entrevistas trata da replicação do questionário desenvolvido por McClelland (1972), composto por 55 afirmativas baseadas em uma escala Likert de cinco pontos, em que são analisadas questões que procuram identificar as dez CCEs. Os maiores e menores valores atribuídos a cada uma das CCEs, bem como a média entre eles, podem ser observados na tabela 5.

Tabela 5 - Média das CCEs dos pesquisadas

\begin{tabular}{lcccc}
\hline Características & $\begin{array}{c}\text { Menor } \\
\text { valor }\end{array}$ & $\begin{array}{c}\text { Maior } \\
\text { valor }\end{array}$ & Média & $\begin{array}{c}\text { Desvio } \\
\text { padrão }\end{array}$ \\
\hline Busca de oportunidade e iniciativa & Categoria realização & & & \\
Persistência & 14 & 22 & 17,86 & 1,98 \\
Comprometimento & 12 & 20 & 16,86 & 1,92 \\
Exigência de qualidade e eficiência & 14 & 21 & 17,50 & 2,08 \\
Correr riscos calculados & 8 & 21 & 17,25 & 2,80 \\
& 10 & 19 & 15,25 & 2,35 \\
\hline Estabelecimento de metas & Categoria planejamento & & & \\
Busca de informações & 10 & 23 & 18,68 & 3,05 \\
Planejamento e monitoramento sistemático & 13 & 24 & 19,50 & 2,91 \\
\hline & 10 & 22 & 17,50 & 2,49 \\
\hline Persuasão e rede de contatos & Categoria poder & \multicolumn{3}{c}{} \\
Independência e autoconfiança & 10 & 21 & 15,14 & 3,07 \\
\hline
\end{tabular}

Fonte: Dados da pesquisa

Ao serem confrontadas as médias obtidas por meio da somatória dos pontos de cada pesquisado para determinada característica, pôde-seobservar a maior e a menor predominância de cada característica,sendo evidenciada através do desvio padrão uma não uniformidade entre o menor e maior valor, revelando uma não homogeneidade do grupo quanto às CCEs, embora todas as características tenham alcançado, na média, a pontuação acima de 15, que McClelland (1972) atribui ao empreendedor.

As três CCEs identificadas com maior predominância nos pesquisados foram: 
$1^{\text {a }}$ - Busca de informações: As respostas obtidas indicam que os pesquisados possuem a tendência de buscar informações para fundamentar e possibilitar a elaboração de estratégias. Para Meyer et al. (2009), a informação é uma das fontes preciosas para a gestão organizacional, com destaque para funções ou ações como planejamento, tomada de decisões, comunicação, avaliação, inovação e criatividade. Os autores complementam ainda que são as informações que levam os gestores à reflexão quanto aos aspectos estratégicos do que fazer, como, quando e para quem.

$2^{\mathrm{a}}$ - Estabelecimento de metas: A pontuação obtida indica que os gestores se preocupam em definir objetivos e estabelecer metas orientadas para resultados. Para Wolf (2014),esse é um fator extremamente importante, principalmente porque, quando se trata de instituições públicas, as metas e os objetivos são traçados no âmbito do sistema, considerando as metas, diretrizes e estratégias do Plano Nacional de Educação.

$3^{a}$ - Busca de oportunidades e iniciativa: De acordo com a percepção dos pesquisados, pode-se dizer que a grande maioria consegue identificar tendências de oportunidade e futuro, bem como, ao tomar iniciativa para fazer, estão dispostos a colocar "a mão na massa". Uma das características próprias do empreendedor, de acordo com Dolabela (2006), é a sua necessidade de encontrar novas oportunidades, buscando novos panoramas para si e para os que o cercam, o que gera,muitas vezes, novos produtos e serviços que contribuem indiscutivelmente para a melhoria na qualidade de vida da população como um todo, posto que aumentam a empregabilidade do mercado e, consequentemente, a geração de renda.

As três CCEs identificadas com menor frequência nos pesquisados foram:

$8^{a}$ - Persistência: Os resultados indicam que os pesquisados precisam desenvolver essa característica para aprimorarem a busca por alternativas, agindo diante de dificuldades e insistindo ou mudando de estratégia com a finalidade de enfrentar os desafios. O empreendedor deve agir repetidamente, ou mudar de estratégia,para enfrentar um desafio ou superar um obstáculo. Filion (1999), ao afirmar que o empreendedor é aquele que possui capacidade de estabelecer objetivos e os perseguir, confirma a persistência como uma característica importante do empreendedor.

$9^{a}$ - Correr riscos calculados: O resultado desta pesquisa indica que a maioria dos pesquisados não gosta de se submeter a situações que implicam riscos e desafios. De acordo com Meyer Jr. et al. (2009), é conhecida a aversão dos gestores universitários ao risco, visto que, na prática, eles não estão habituados a correr riscos e os evitam na maioria das vezes. Para os autores, os gestores de IFES precisam saber ousar e correr riscos para enfrentar um mundo competitivo por ideias, conhecimentos, recursos, pessoas qualificadas e serviços educacionais de reconhecida qualidade.

$10^{a}$ - Persuasão e rede de contatos: Os resultados evidenciam que essa é uma característica menos evidente nos pesquisados. Filion e Dolabela (2000) ressaltam que o empreendedor precisa cercar-se das pessoas certas para crescer, ele deve ser capaz de atrair pessoas competentes às quais possa pedir conselhos. Para Wolf (2014), gestores que não desenvolvem uma rede de relacionamentos, tanto interna quanto externa ao polo de educação, certamente terão suas possibilidades reduzidas, limitando seu desempenho profissional e, por conseguinte, sua motivação, satisfação e realização no trabalho.

Os resultados das pesquisas de McClelland (1972) revelaram que, entre os motivos para empreender, a necessidade de realização é a mais forte entre as três características.Nesta pesquisa, no entanto, como pode ser visualizado na tabela 5 , as duas características de maior predominância (busca de informações e estabelecimento de metas) pertencem à necessidade de planejamento, e a terceira característica pertence à necessidade de realização (busca de oportunidades e iniciativa).

\subsection{Ambiente da instituição quanto ao desenvolvimento das características empreendedoras}

A quarta parte do roteiro de entrevistas constou de cinco questões de múltipla escolha que tinham por objetivo analisar o ambiente da instituição quanto ao desenvolvimento de características empreendedoras. Foram dadas alternativas aos pesquisados, convidando-os a justificar seu posicionamento.

Em relação à primeira questão (Como você classifica seu ambiente de trabalho?), as alternativas com maior predominância foram "extremamente burocrático" e "dá espaço para pessoas criativas e inovadoras", 
seguidas por "participativo". Os percentuais obtidos evidenciam uma falta de consenso dos respondentes, demonstrando que, embora haja em alguns setores normas rígidas e extrema burocracia, outros alguns setores conseguem oferecer espaço para as pessoas inovadoras e criativas.

Fischborn (2004) salienta que não basta uma cultura organizacional flexível, aberta a inovações, para fazer com que o funcionário se torne empreendedor, mas que esse tipo de ambiente pode abrir os caminhos necessários para que os indivíduos com uma personalidade empreendedora encontrem na sua organização um ambiente que considerem sua maneira de enxergar o mundo como um diferencial poderoso.

Para a segunda questão (Dos itens a seguir, assinale aqueles que, do seu ponto de vista, são considerados essenciais para a implantação de um ambiente propício à atuação do empreendedor), as alternativas mais assinaladas foram "planejamento estratégico", "definição ou indicadores de qualidade" e "estímulo à criatividade e à inovação".

$\mathrm{Na}$ terceira questão (Dos itens a seguir, assinale aqueles que você considera como barreira à criação de um ambiente empreendedor nas universidades), as principais alternativas assinaladas foram "funcionários desmotivados", "burocracia", "falta de liberdade para criar" e "política organizacional".

Pinchot (1989) explica que a medida fundamental de progresso para o intraempreendedor é a crescente liberdade para utilizar recursos corporativos para construir novos negócios para a corporação,pois o que quer que o homem queira fazer, a liberdade traz novas maneiras de fazê-la melhor. O autor complementa ainda que, para a eficiência nos empreendimentos, é preciso criar uma atmosfera de liberdade, na qual todas as opiniões sejam respeitadas e também em que haja uma forma rápida de resolver os problemas para seguir em frente. Na visão do autor,esse tipo de ação ultrapassa os conceitos tradicionais de hierarquia e gera espaço e liberdade para que todos possam contribuir de forma ativa.

Na quarta questão do roteiro de entrevistas (É feito algum tipo de planejamento nesta instituição? Qual?) e na quinta questão (Qual a periodicidade deste planejamento?), a maioria dos pesquisados (89,29\%) afirmou que existe algum tipo de planejamento na instituição, mas apenas $35,71 \%$ indicaram o planejamento estratégico como o tipo de planejamento feito na instituição, indicando um possível desconhecimento a respeito do tema. Percebe-se que os pesquisados não dominam na íntegra a abrangência do planejamento feito na instituição, pois, quando questionados sobre os fatores essenciais para a implantação de um ambiente propício à atuação do empreendedor na universidade (segunda questão), a grande maioria dos pesquisados $(92,86 \%)$ indicou o planejamento estratégico.

\section{Considerações finais}

A análise dos dados qualitativos e quantitativos permitiu verificar que a concepção de empreendedorismo está compartilhada e difundida de forma bastante homogênea entre os pesquisados, os quais o relacionam à "motivação para inovar, mudar e criar", ao "desenvolvimento de ideias, projetos e serviços", à "criação de uma empresa ou negócio" e à "criação de novos negócios ou implementação de produtos e serviços em uma empresa já existente".

Quanto ao que é ser um empreendedor no ambiente universitário, verificou-se que as ideias e definições relativas à questão não estão compartilhadas e difundidas de forma tão homogênea entre os pesquisados como no item anterior, havendo uma maior predominância de respostas categorizadas, tais como: "Conceber e promover novas formas de transmissão de conhecimento" e "ser um gestor não burocrático".

Ao serem consultados sobre a importância do empreendedorismo como forma de gestão nas universidades, verificou-se que houve grande semelhança nas respostas, com maior predominância de respostas categorizadas como: "É uma forma de ultrapassar as limitações próprias de uma instituição pública", seguida por "pode resultar no desenvolvimento de uma cultura empreendedora".

Como ações empreendedoras nas universidades, houve uma maior predominância de respostas categorizadas, como: "Incentivo à criação e organização de projetos e eventos acadêmicos e científicos", seguida por "uso da tecnologia e gestão das atividades pedagógicas". 
Ao buscar identificar as características empreendedoras segundo a abordagem comportamentalista de McClelland (1972), verificou-se que, embora tenha sido observada uma não uniformidade entre o menor e maior valor, revelando uma não homogeneidade do grupo quanto às CCEs, todas as características alcançaram a média da pontuação que McClelland atribui ao empreendedor. Mesmo que a análise geral tenha se concentrado não nos resultados individuais, e sim no resultado global, foi identificada a presença de todas as CCEs. As características com pontuação mais alta foram "busca de informações", "estabelecimento de metas" e "busca de oportunidade e iniciativa", e as características com pontuação mais baixa foram "persistência", "correr riscos calculados", "persuasão e rede de contatos".

Procurou-se analisar também o ambiente da instituição a partir de como os gestores classificam o ambiente de trabalho, dos fatores considerados essenciais para a implantação do ambiente empreendedor e dos fatores considerados como barreiras à criação de um ambiente empreendedor. Verificou-se que os pesquisados classificam o ambiente de trabalho como "extremamente burocrático", que "dá espaço para pessoas criativas e inovadoras", e "participativo". Os percentuais obtidos evidenciam uma falta de consenso entre os respondentes, indicando que, apesar do ambiente burocrático existente em alguns setores, outros conseguem oferecer espaço para as pessoas inovadoras e criativas.

Os itens essenciais para a implantação de um ambiente propício à atuação do empreendedor foram "planejamento estratégico" e "definição ou indicadores de qualidade", seguidas por "estímulo à criatividade e à inovação" e "conhecimento e identificação da demanda para criação de novos produtos e serviços". As principais alternativas assinaladas como barreira à criação de um ambiente empreendedor foram "funcionários desmotivados" e "burocracia", seguidas por "falta de liberdade para criar", "política organizacional" e "restrições orçamentárias".

Observou-se que os pesquisados parecem estar cientes da importância tanto dagestão empreendedora nas universidades como também do que é necessário e do que dificulta sua implantação. Correlacionandose o ambiente da instituição e o desenvolvimento das CCEs, compreende-se que as dificuldades estão relacionadas a certas condições que possibilitam sua execução e favorecem a implantação de um ambiente propício para a gestão empreendedora, tais como: planejamento estratégico, definição ou indicadores de qualidade, e estímulo à criatividade e à inovação.

Com base nos resultados obtidos, considera-se que os objetivos propostos para a pesquisa foram atingidos. Conclui-se que o desafio que se apresenta é criar um ambiente que propicie o desenvolvimento do espírito empreendedor, no sentido de estimular o aperfeiçoamento das CCEs, e é importante saber que tais características podem ser desenvolvidas por todos.Para tanto, a cultura empreendedora precisa ser disseminada, fazendo com que cada vez mais indivíduos convivam num ambiente empreendedor, pois ele estimula o desenvolvimento econômico, gerando inovação, tecnologia, emprego e renda. Além de contribuir para o desenvolvimento econômico da sociedade, a atividade empreendedora faz com que os indivíduos se sintam cada vez mais realizados, conciliando o trabalho com o prazer e o crescimento pessoal, profissional e social. Fazer esta reflexão no âmbito das organizações públicas, entretanto, requer a superação de algumas barreiras impostas pelo próprio formato do modelo de gestão dessas instituições.

Com base no estudo realizado, constatou-se que as normas que regulam o setor público restringem a atuação dos gestores, desestimulando uma atuação mais empreendedora. Cabe ressaltar, contudo, que elas não impedem que o empreendedorismo se faça presente nessas organizações. De modo geral, pode-se dizer que a cultura organizacional de uma IES possui particularidades que somente podem ser identificadas quando se procede a estudos específicos, de forma que se recomenda o aprofundamento e a continuidade desta pesquisa.

Vale ressaltar que este trabalho limitou-se apenas aos gestores lotados na Escola de Minas, de forma que os resultados obtidos devem ser comparados em pesquisas direcionadas aos gestores de outras Unidades da UFOP ou da administração superior, bem como com uma pesquisa direcionada aos técnicos administrativos e aos discentes. Recomenda-se também uma que esta pesquisa seja replicada 
com gestores de IES privadas, realizando-se uma comparação que identifique em que tipo de instituição o ambiente é mais propício para o desenvolvimento do comportamento empreendedor dos gestores.

\section{Referências}

Barlach, L. (2014). Comportamento empreendedor: Um estudo empírico baseado no referencial de McClelland. Revista de Carreiras e Pessoas (ReCaPe), 4(3), 272-281.Recuperado de http://revistas. pucsp.br/index.php/ReCaPe/article/view/21837

Coelho, M. L. G. M. M. (2010). Intraempreendedorismo e a inovação na gestão pública federal. Revista do Serviço Público, 6(3), 233-247. Recuperado de http://seer.enap.gov.br/index.php/RSP/article/ view/48/44

Dolabela, F. (2006). O segredo de Luísa: Uma ideia, uma paixão e um plano de negócios: Como nasce o empreendedor e se cria uma empresa (14a ed.). São Paulo: Cultura.

Dornelas, J. C. A. (2008). Empreendedorismo corporativo: Como ser empreendedor, inovar e se diferenciar na sua empresa (2a ed.). Rio de Janeiro: Elsevier.

Emmendoerfer, M. L., Valadares, J. L., \& Balbi, R. V. (2008). Esforços para a construção do conhecimento sobre "Empreendedorismo Interno": Reflexões e perspectivas a partir de Eventos da ANPAD (19972007). Anais do XXVI Simpósio de Gestão de Inovação Tecnológica, Brasília, DF, Brasil.

Figueiredo, M. Z. A., Chiari, B. M., \& Goulart, B. N. G. (2013). Discurso do Sujeito Coletivo: Uma breve introdução à ferramenta de pesquisa qualiquantitativa. DistúrbComun, 25(1), 129-136.

Filion, L. J. (1999). Empreendedorismo: Empreendedores e proprietários-gerentes de pequenos negócios. Revista de Administração da USP, 34(2), 05-28.

Filion, L. J., \& Dolabela, F. (2000). Boa ideia e agora? São Paulo: Cultura.

Fischborn, M. L. N. (2004). Empreendedorismo nas instituições de ensino superior do estado de Santa Catarina, Brasil. (Dissertação de Mestrado em Administração, Universidade Regional de Blumenau, Blumenau, SC, Brasil).

Hashimoto, M. (2009). Organizações intraempreendedoras: Construindo a ponte entre clima interno e desempenho superior. (Tese de Doutorado, Fundação Getúlio Vargas, São Paulo, SP, Brasil).

Lefèvre, F., \& Lefèvre, A. M. C. (2004). O pensamento coletivo como soma qualitativa. Recuperado de http://www.fsp.usp.br/quali-saude/soma\%20qualitativa\%209\%20de\%20fevereiro\%20de\%202004.htm

Lefèvre, F., \& Lefèvre, A. M. C. (2006). O sujeito coletivo que fala. Interface: Comunicação, Saúde, Educação, 10(20), 517-24.

Lizote, S. A., Lana, J. A., Gauche, S., \& Verdinelli, M. A. (2013). Comportamento intraempreendedor: Um estudo em Instituições de Ensino Superior. Revista Gestão Universitária na América Latina, 6(1), 233252.

Marques, R. A. C. (2012). Empresa júnior: Espaço para construção de competências. (Dissertação de Mestrado, Universidade Federal de Uberlândia). Recuperado de https://repositorio.ufu.br/ bitstream/123456789/11975/1/d.pdf

Marra, A. V., \& Melo, M. C. O. L. (2007). Docente-gerente: O cotidiano de chefes de departamento e coordenadores em uma universidade federal. Anais do XXVII Encontro da Associação Nacional dos Programas de Pós-Graduação em Administração, Atibaia, SP, Brasil.

McClelland, D. C. (1972). A sociedade competitiva: Realização e progresso social. Rio de Janeiro: Expressão e Cultura.

Meyer, V., Jr., Meyer, B., \& Rocha, R. A. da. (2009). Empreendedorismo na gestão universitária: Um estudo de caso. Revista Gestão Organizacional, 2(1), 49-62. 
Pinchot, G. (1989). Intrapreneuring: Porque você não precisa deixar a empresa para tornar-se um empreendedor. São Paulo: Harbra.

Prado, M. L., Machado, E., Melo, M. B., \& Lapolli, E. M. (2011). Análise do Perfil Intraempreendedor de Servidores de Instituição de Ensino Superior. Anais do XI Colóquio Internacional sobre Gestão Universitária na América do Sul, Florianópolis, SC, Brasil.

Rosa, L. A. B. da, Gomes, C. M., Perlin, A. P., Motke, F. D., \& Frizzo, K. (2015). O estado da arte sobre a temática empreendedorismo. Revista Ciências Administrativas, 21(2), 600-620.

Schmitz, A. L. F. (2012). Competências empreendedoras dos gestores de instituições de ensino superior. Anais do XII Colóquio Internacional sobre Gestão Universitária nas Américas, Florianópolis, SC, Brasil.

Silva, G. M., \& Emmendoerfer, M. L. (2013). Ciclo de vida das organizações, empreendedorismo e liderança administrativa: Contribuições e reflexões para os estudos organizacionais. Revista Ciências Administrativas, 19(1), 145-165.

Universidade Federal de Ouro Preto (2010). Resolução CUNI 1174: Aprova o plano de desenvolvimento institucional da UFOP. Recuperado de http://www.ufop.br/pdi/wp-content/uploads/2010/08/PDI_ UFOP_2011-2015_Aprovada_Verso-Final.pdf

Universidade Federal de Ouro Preto (2015). Informações consolidadas. Recuperado de https://zeppelin3. ufop.br:38182/cgp/paginas/inicio.faces

Valadares, J. L., Emmendoerfer, M. L., Alves, R. C. M., \& Morais, M. C. A. (2012). O fenômeno do empreendedorismo público: Um ensaio sobre a aplicabilidade desse construto na administração pública brasileira. Anais do $36^{\circ}$ Encontro Nacional da Associação Nacional dos Programas de PósGraduação em Administração, Rio de Janeiro, RJ, Brasil.

Vidal, F. A. B., \& Santos, J. L. F. (2003). Comportamento Empreendedor Gerente: Proprietário influenciando na vantagem competitiva de uma empresa varejista de médio porte. Anais do $27^{\circ}$ Encontro Nacional da Associação Nacional dos Programas de Pós-Graduação em Administração, Atibaia, SP, Brasil.

Walter, S. A., Rocha, D.T., Domingues, M. J. C. S., \& Tontine, G. (2007). De professor a gestor: Uma análise do perfil dos gestores dos cursos de administração das instituições de ensino superior da região oeste do Paraná. Revista ANGRAD,8(1), 53-72.

Wolf, S. M. (2014). Influência da Competência Empreendedora dos coordenadores nos indicadores de desempenho dos polos EaD. (Tese de Doutorado, Universidade Federal de Santa Catarina, Florianópolis, Brasil).

Submetido em: 11/02/2017

Aprovado em: 19/04/2017 